\title{
Análise dos Balanços Sociais de duas empresas do setor têxtil de Santa Catarina
}

\author{
Analysis of Social Balances of two companies in the textile \\ sector of Santa Catarina \\ Stephane Louise Boca Santa \\ stephanelou.bs@gmail.com \\ UFSC \\ Elisete Dahmer Pfitscher \\ elisete@cse.ufsc.br \\ UFSC
}

\begin{abstract}
Resumo
O setor têxtil é um dos setores importantes de Santa Catarina e as indústrias aqui implantadas, tem demanda a todo Brasil e inclusive ao exterior. Por isso foram escolhidas duas empresas deste setor para fazer uma análise do Balanço Social, visto que hoje se faz cada vez mais necessário investir no meio ambiente e na sociedade. Assim, o objetivo geral deste trabalho é verificar os investimentos nos indicadores sociais internos e externos de duas empresas do ramo têxtil. Como objetivos específicos têm-se realizar análise vertical e horizontal dos indicadores sociais internos e indicadores sociais externos, considerando outros indicadores mencionados. Os dados foram analisados buscando compreender as informações disponibilizadas por meio dos Balanços Sociais das duas empresas, como também uma das empresas respondeu uma entrevista semi-estruturada enviada. Conclui-se que as duas empresas investem em questões sociais e coincidem em alguns indicadores sociais. A empresa A utiliza Balanço Social IBASE, enquanto a empresa B, Balanço Social próprio. Além disso, as empresas demonstram interesses sociais e ambientais, mas não mostram ainda todos os valores monetários dos investimentos.
\end{abstract}

Palavras-chave: Análise de Indicadores. Balanço Social. Setor têxtil.

\begin{abstract}
The textile sector is one of the most important of Santa Catarina and the industries established here is demanded by the full Brazil and even abroad. So, two companies from this sector were chosen to have their Social Balance analyzed, since today is more and more necessary investing in the environmentand society. In this study were made vertical and horizontal analysis of the internal and external social indicators, considering all the available indicators to the conclusions completions of the data obtained by analysis. After the analysis, the both companies' values in percentage are going to be compared. The data were analyzed in order to understand the information available through the Social Balance of both companies, but also one of the companies responded to a semi-structured interview sent. Is concluded that company A and company B invest in social issues, but much remains to be worked in this area. In addition, companies demonstrate social and environmental interests, but also show the monetary values of all investments.
\end{abstract}

Key words: Social Report. Indicators Analysis. Textile company

Artigo recebido em: 26.02.2012; Aceito em: 30.03.2012

R. Cont. Ufba, Salvador-Ba, v. 6, n. 1, p. 66-79, janeiro-abril 2012 


\section{INTRODUÇÃO}

Com as crescentes preocupações com o meio social e ambiental, a Contabilidade precisou adaptar-se a nova realidade e exigência do mercado. Assim, um novo campo da Contabilidade surgiu: a Contabilidade Social e Ambiental. Para uma melhor demonstração do investimento das empresas na área social e ambiental, é utilizado o Balanço Social, do qual há vários modelos. Entretanto, neste trabalho, adota-se o modelo sugerido pelo Instituto Brasileiro de Análises Sociais e Econômicas - IBASE, Instituto ETHOS e o relatório de sustentabilidade Global Reporting Initiative - GRI.

Muitas empresas além de divulgar o Balanço Social, divulgam as informações através de relatórios de sustentabilidade, o qual evidenciamos o GRI, pois conforme o sítio eletrônico do Instituto Ethos (2011) “ O relatório de sustentabilidade é a principal ferramenta de comunicação do desempenho social, ambiental e econômico das organizações. O modelo de relatório da Global Reporting Initiative (GRI) é atualmente o mais completo e mundialmente difundido", as empresas estudadas têm além do Balanço Social, os Relatórios de Sustentabilidade, mas não foram foco do presente estudo.

Devido ao grau de importância das pesquisas na área socioambiental, o presente estudo analisa duas empresas do ramo têxtil do Estado de Santa Catarina, com o objetivo de verificar os seus investimentos ambientais e sociais, no intuito de responder a seguinte problemática: os dados dos Balanços Sociais condizem com as realidades das empresas e os indicadores têm evoluído de um ano para o outro? Para atender aos propósitos desta pesquisa, fez-se a análise vertical e a horizontal dos Balanços Sociais das duas empresas nos anos de 2008 e 2009. Destes balanços, serão considerados os Indicadores Sociais Internos e Indicadores Sociais Externos, todavia todos os indicadores influenciam na análise do trabalho. Outra questão foi quanto à inflação, pois não foi considerada nos períodos de 2008 e 2009.

\section{RECURSOS METODOLÓGICOS}

Objetivando analisar os Balanços Sociais de duas empresas do ramo têxtil, realiza-se uma pesquisa bibliográfica para revisar os conceitos do tema proposto e para identificar as informações e dados necessários para o estudo.

A pesquisa bibliográfica é realizada com base em publicações, tradicionalmente livros e materiais impressos. No entanto, as pesquisas têm incluído outros tipos de fontes, disponibilizadas por meio digital. (GIL; 2010, p. 29). Neste estudo, praticamente todas as informações foram pesquisadas por meio digital, com exceção do referencial teórico, que possui também informações de meio impresso.

Para a coleta de dados referente às empresas, a técnica de pesquisa empregada foi a documental, que, segundo Marconi e Lakatos (2009, p. 176) "está restrita a documentos, escritos ou não, constituindo o que se denomina de fontes primárias." Os documentos utilizados foram os balanços sociais das empresas A e B do período 2008 e 2009. Optou-se por denominá-las neste estudo de A e B para preservar suas identidades.

A empresa A disponibiliza seus Balanços Sociais no modelo sugerido pelo IBASE. A empresa B não menciona o modelo adotado e, ao que parece, utiliza modelo próprio. Em vista disso, utiliza-se o Balanço Social modelo IBASE divulgado pela empresa A, enquanto que o Balanço Social da empresa B será adaptado para fins de análise deste estudo. 
Para a análise vertical e horizontal foram utilizados os Indicadores Sociais Internos e Externos, no entanto, para fins de conclusão e interpretação dos dados, foram levados em consideração outros indicadores do Balanço Social.

O problema é abordado de forma qualitativa. De acordo com Richardson (1999, p. 80):

Os estudos que empregam uma metodologia qualitativa podem descrever a complexidade de determinado problema, analisar a interação de certas variáveis, compreender e classificar processos dinâmicos vividos por grupos sociais, contribuir no processo de mudança de determinado grupo e possibilitar, em maior nível de profundidade, o entendimento das particularidades do comportamento dos indivíduos.

Os dados foram analisados buscando compreender as informações disponibilizadas pelas duas empresas, realizando análises e sugestões. Além disso, uma das empresas respondeu uma entrevista semi-estruturada enviada por e-mail, fazendo com que as informações tivessem caráter fidedigno.

Utilizam-se os Balanços Sociais das duas empresas, referentes aos anos de 2008 e 2009, para realizar a análise vertical e horizontal dos indicadores sociais internos e indicadores sociais externos de cada uma das empresas. Quanto à análise vertical, Padoveze (2010, p. 200) afirma que "os percentuais obtidos por essa análise devem sempre ser analisadas em conjunto com os dados da análise horizontal e os indicadores básicos." Já a respeito da análise horizontal, Padoveze (2010, p. 207) diz que "a análise horizontal é o instrumento que calcula a variação percentual ocorrida de um período para o outro, buscando evidenciar se houver crescimento ou decrescimento do item analisado".

Para as análises, são considerados outros indicadores e informações disponibilizadas pelas empresas através do sitio eletrônico. Também é importante esclarecer que não foi considerada a inflação.

A trajetória metodológica divide-se em três fases. A primeira da "Revisão Teórica", onde são estudados os temas: Responsabilidade Social e Ambiental: Contabilidade Ambiental e Balanço Social, IBASE, ETHOS e GRI.

$\mathrm{Na}$ segunda fase, apresenta-se a "Análise de Resultados", onde primeiramente faz-se um breve histórico das empresas pesquisadas. Após efetua-se a "Análise do Balanço Social" de cada uma das empresas.

E na terceira fase, a conclusão da análise e resultados apresentados.

\section{REVISÃO TEÓRICA}

Apresenta-se na revisão teórica a Responsabilidade Social e Ambiental, trata-se assim de temas referentes à Contabilidade Ambiental e ao Balanço Social. São evidenciados dois modelos de Balanço Social, quais sejam: IBASE e ETHOS; e também o Relatório de Sustentabilidade Global Reporting Iniciative - GRI.

\subsection{Responsabilidade Social e Ambiental: Contabilidade Ambiental e Balanço Social}

Um dos objetivos da Contabilidade é fornecer dados aos seus usuários para a tomada de decisão. O usuário pode ser qualquer pessoa que tenha interesse nos dados de determinada 
entidade. Essas informações são normalmente levantadas e fornecidas pela contabilidade. (MARION, 2005)

A Contabilidade trazia primeiramente, informações somente do interesse dos administradores; no entanto, ao longo do tempo, começou a ser exigido pelos funcionários das grandes indústrias que as entidades fornecessem também informações sociais, e devido a este processo, surgiu a necessidade de elaborar o demonstrativo denominado Balanço Social. (TINOCO; KRAEMER, 2008)

Principalmente com a revolução industrial, novas preocupações surgiram com o destino dos resíduos das indústrias, das residências, com a escassez de recursos energéticos, que afetam o meio ambiente e a vida das pessoas. $\mathrm{O}$ que se deve fazer para amenizar este problema e continuar fabricando e consumindo sem degradar o meio ambiente, é uma questão preocupante para toda a população. Por isso, surgiram leis, estudos, entre outros, buscando solucionar todo ou parte do problema.

As empresas passaram a ter o compromisso e a obrigação de seguir leis, realizar projetos e preocupar-se com o meio ambiente; mesmo os clientes passaram a exigir essa atitude das empresas, e isso influenciou inclusive na concorrência. Por isso, há a necessidade de contabilizar os investimentos nesta área e apresentá-los aos usuários. Uma maneira é realizando esta tarefa por meio do Balanço Social e relatórios, mostrando a responsabilidade social e ambiental. Conforme Tachizawa (2004, p. 73):

a responsabilidade social e ambiental pode ser resumida no conceito de "efetividade", como o alcance de objetivos do desenvolvimento econômico-social. Portanto, uma organização é efetiva quando mantém uma postura socialmente responsável.

Assim justifica-se a necessidade de estudar os balanços sociais das empresas e analisar os dados a fim de verificar se há realmente postura social.

Balanço Social é, conforme Tinoco e Kraemer (2008, p. 28):

um instrumento de gestão e de informação que visa evidenciar, de forma mais transparente possível, informações financeiras, econômicas, ambientais e sociais, do desempenho das entidades, aos mais diferenciados usuários, seus parceiros sociais.

Uma das melhores formas de demonstrar investimentos e ter um instrumento de gestão para a empresa e gestores, e ao mesmo tempo é útil aos clientes, fornecedores e usuários em geral.

\subsection{IBASE, ETHOS e Global Reporting Iniciative - GRI}

Há diversos modelos de Balanço Social, neste estudo evidenciam-se dois destes: o modelo do IBASE e o ETHOS. Também se apresenta o relatório de sustentabilidade Global Reporting Iniciative.

Conforme o Instituto Brasileiro de Análises Sociais e Econômicas (IBASE), o Balanço Social é composto pelos seguintes itens:

1. Base de Cálculo

2. Indicadores Sociais Internos

3. Indicadores Sociais Externos

4. Indicadores Ambientais 
5. Indicadores do Corpo Funcional

6. Informações relevantes quanto ao exercício da cidadania empresarial

7. Outras Informações

No Balanço Social modelo IBASE, o indicador social interno refere-se a gastos com alimentação, educação, capacitação e saúde, dentre outros relacionados aos empregados. Já o indicador social externo, refere-se a gastos da empresa na comunidade, como por exemplo, saúde e saneamento, cultura, educação, esportes, também são considerados neste indicador os tributos. (PFITSCHER, 2009)

O Instituto ETHOS foi fundado com o objetivo de assessorar empresas quanto a responsabilidade social empresarial e fazer com que essas empresas incorporem esses conceitos a sua gestão. (Sítio eletrônico ETHOS, 2011) O ETHOS sugere maior detalhamento que o IBASE, e é dividida em quatro partes, sendo elas: apresentação, com a missão e visão da empresa, mensagem do presidente, perfil, e setor da economia; empresa, com o histórico da empresa, princípios e valores, estrutura, funcionamento e governança corporativa; atividade empresarial, com indicadores de desempenho e diálogos com as partes interessadas; e anexos, contendo o Balanço Social no modelo IBASE, e demais interesses da sociedade, como projetos sociais. (PFITSCHER, 2009)

O GRI é um relatório de sustentabilidade que surgiu em 1997, e tornou-se independente em 2002. É dividido em seis categorias. São estes os indicadores: de Desempenho Econômico; do Meio Ambiente; de Práticas Trabalhistas e Desempenho Decente; de Direitos Humanos; Sociais (referente à sociedade); e de Responsabilidade pelo Produto. (PFITSCHER, 2009, p. 24) De acordo com o sítio eletrônico do Instituto Ethos (2011):

A GRI foi criada com o objetivo de elevar as práticas de relatórios de sustentabilidade a um nível de qualidade equivalente ao dos relatórios financeiros. $\mathrm{O}$ conjunto de diretrizes e indicadores da GRI proporciona a comparabilidade, credibilidade, periodicidade $\mathrm{e}$ legitimidade da informação na comunicação do desempenho social, ambiental e econômico das organizações.

Portanto, a fim de alcançar um padrão elevado de informações foi criada a GRI, proporcionando a possibilidade de análises e comparação de qualidade.

\section{ANÁLISE DOS RESULTADOS}

Apresenta-se neste item um breve histórico das empresas pesquisadas e, após, a análise vertical, a horizontal e a interpretação dos dados de indicadores sociais internos e externos das empresas A e B, levando em consideração o corpo funcional destas empresas.

\subsection{Breve histórico das empresas pesquisadas}

A empresa A começa as suas atividades em 22 de maio de 1964. Em 1975, instala parque fabril, em Santa Catarina. A partir disso lança várias marcas que fizeram e fazem muito sucesso. Em 1990, lança o Programa de Participação dos Colaboradores nos Resultados da empresa. E em 2000, obtém a certificação ISO 14001 (norma internacionalmente aceita referente a Sistema de Gestão Ambiental). Outro grande passo foi constituir filiais na Europa e no México. (Sites pesquisados) 
A empresa B, foi fundada em 1880, em Santa Catarina. Um de seus fundadores recebeu um título muito importante, ainda no século XIX, de "Pioneiro nas Atividades em Favor da Preservação da Natureza em Terras Brasileiras". Desde 1973 possui unidades de tratamento de efluentes e durante a década de 80, tinha projetos de reflorestamento. Durante a década de 90, obteve todos os chamados "selos verdes" europeus, como por exemplo o "Ecotex" e "Okotex". (Sites pesquisados)

\subsection{Análise do Balanço Social da empresa A}

Analisa-se os indicadores sociais internos relacionando-os com o corpo funcional da empresa. Tanto no período de 2008 quanto no de 2009, o indicador social interno mais expressivo é de Encargos Sociais Compulsórios, com 6,09\% e 6,22\% respectivamente. Já na análise horizontal, não chegou a ser destaque.

O indicador com maior variação positiva na análise horizontal é o Participação nos Lucros ou Resultados, com $95,88 \%$ de aumento.

Outra variação relevante em 2008 foi com o indicador Outros, com 1,40\%, este valor aumentou em 2009, para 1,67\%, sendo o indicador mais expressivo do ano referido, depois dos encargos sociais compulsórios. Na análise horizontal, houve crescimento de 32,32\%.

Tabela 1 - Análise dos indicadores internos

\begin{tabular}{|c|c|c|c|c|c|c|}
\hline $\begin{array}{l}\text { 1 - BASE DE } \\
\text { CÁLCULO }\end{array}$ & \multicolumn{3}{|c|}{2009} & \multicolumn{2}{|l|}{2008} & $\begin{array}{c}\text { Análise } \\
\text { Horizontal }\end{array}$ \\
\hline Receita líquida (RL) & \multicolumn{3}{|c|}{$\begin{array}{c}\mathrm{R} \$ \\
390.277 .000,00\end{array}$} & \multicolumn{2}{|c|}{$\begin{array}{c}\mathrm{R} \$ \\
352.650 .000,000\end{array}$} & 10,67 \\
\hline $\begin{array}{l}2 \text { - INDICADORES } \\
\text { SOCIAIS } \\
\text { INTERNOS }\end{array}$ & & VALOR & $\begin{array}{l}\text { AV } \\
(\%)\end{array}$ & VALOR & $\begin{array}{l}\mathrm{AV} \\
(\%)\end{array}$ & AH (\%) \\
\hline Alimentação & $\mathrm{R} \$$ & $5.483 .000,00$ & 1,40 & $\mathrm{R} \$ 5.308 .000,000$ & 1,51 & 3,30 \\
\hline $\begin{array}{l}\text { Encargos sociais } \\
\text { compulsórios }\end{array}$ & $\mathrm{R} \$$ & $4.291 .000,00$ & 6,22 & $\begin{array}{c}\mathrm{R} \$ \\
21.478 .000,000\end{array}$ & 6,09 & 13,10 \\
\hline $\begin{array}{l}\text { Segurança e saúde no } \\
\text { trabalho }\end{array}$ & $\mathrm{R} \$$ & $165.000,00$ & 0,04 & $\begin{array}{c}\mathrm{R} \$ \\
174.000,00\end{array}$ & 0,05 & $-5,17$ \\
\hline $\begin{array}{l}\text { Creches ou auxílio- } \\
\text { creche }\end{array}$ & $\mathrm{R} \$$ & $399.000,00$ & 0,10 & $\begin{array}{c}\mathrm{R} \$ \\
417.000,00\end{array}$ & 0,12 & $-4,32$ \\
\hline $\begin{array}{l}\text { Participação nos } \\
\text { lucros ou resultados }\end{array}$ & $\mathrm{R} \$$ & $5.040 .000,00$ & 1,29 & $\begin{array}{c}\mathrm{R} \$ \\
2.573 .000,00\end{array}$ & 0,73 & 95,88 \\
\hline Outros & $\mathrm{R} \$$ & $6.522 .000,00$ & 1,67 & $\mathrm{R} \$$ & 1,40 & 32,32 \\
\hline
\end{tabular}




\begin{tabular}{l|c|c|c|c|c}
\cline { 5 - 5 } & & & $4.929 .000,00$ & & \multicolumn{1}{c}{} \\
\hline $\begin{array}{l}\text { Total - Indicadores } \\
\text { sociais internos }\end{array}$ & $\mathrm{R} \$ 46.161 .000,00$ & 11,83 & $\begin{array}{c}\mathrm{R} \$ \\
38.540 .000,00\end{array}$ & 10,93 & 19,77 \\
\hline
\end{tabular}

Fonte: dados pesquisados (2011)

Quanto ao indicador Alimentação, destacou-se em 2008 com 1,51\%, no entanto teve queda em 2009 ficando em 1,40\%. Além disso, verifica-se que no indicador do corpo funcional o número de empregos também reduziu de 2008 para 2009. Pode-se então concluir, que a redução da Alimentação, pode ter ocorrido em consequiência da redução de empregados e que, provavelmente, não houve maiores investimentos. No entanto, na análise horizontal, verificase um crescimento de 3,30\% em 2009, em relação ao período anterior. A Tabela 2 apresenta os indicadores do corpo funcional.

Tabela 2 - Indicadores do corpo funcional

\begin{tabular}{|c|c|c|}
\hline 5 - INDICADORES DO CORPO FUNCIONAL & 2009 & 2008 \\
\hline $\mathrm{N}^{\mathrm{o}}$ de empregados (as) ao final do período & 5,862 & 5,874 \\
\hline $\mathrm{N}^{\mathrm{o}}$ de admissões durante o período & 2,219 & 2,02 \\
\hline $\mathrm{N}^{\mathrm{o}}$ de empregados (as) terceirizados (as) & 195 & 199 \\
\hline No de estagiários (as) & 72 & 43 \\
\hline $\mathrm{N}^{\mathrm{o}}$ de empregados (as) acima de 45 anos & 363 & 313 \\
\hline $\mathrm{N}^{\mathrm{o}}$ de mulheres que trabalham na empresa & 4,152 & 4,096 \\
\hline$\%$ de cargos de chefia ocupados por mulheres & $52.00 \%$ & $47.40 \%$ \\
\hline $\mathrm{N}^{\mathrm{o}}$ de negros (as) que trabalham na empresa & 1,718 & 1,795 \\
\hline$\%$ de cargos de chefia ocupados por negros (as) & $13.00 \%$ & $17.19 \%$ \\
\hline $\begin{array}{l}\mathrm{N}^{\mathrm{o}} \text { de portadores (as) de deficiência ou necessidades } \\
\text { especiais }\end{array}$ & 56 & 73 \\
\hline \multicolumn{3}{|l|}{$\mathrm{N}^{\mathrm{o}}$ de demissões e saídas no período } \\
\hline $\mathrm{N}^{\mathrm{o}}$ de pessoas beneficiadas com o primeiro emprego & & \\
\hline
\end{tabular}

Fonte: dados pesquisados (2011) 
Os indicadores sociais internos com menor relevância no Balanço Social foram, em primeiro lugar, Segurança e Saúde no Trabalho, em 2008 com 0,05\% e queda de 0,04\% em 2009. Na análise horizontal, destaca-se com a maior redução de investimentos, com $-5,17 \%$. Percebe-se que provavelmente este valor caiu em consequência à queda do número de empregados ou redução de investimento nesta área.

Analisando o indicador Informações Relevantes quanto ao Exercício da Cidadania Empresarial, verifica-se que houve, em 2008, 73 acidentes de trabalho e 64 em 2009. Isso significa que, em 2008, 1,24\% do total de funcionários sofreu acidentes de trabalho e, em 2009, houve queda de $1,09 \%$ dos acidentes. Não foi localizada norma ou lei que define se há uma margem permitida para acidentes de trabalho.

É importante mencionar que o indicador Creche ou Auxílio Creche teve queda nos investimentos, segundo a análise horizontal, de $-4,32 \%$. Pode-se comprovar esta redução ao se realizar a análise vertical, uma vez que, em 2008 , houve $0,12 \%$ e, em 2009 , houve $0,10 \%$ dos investimentos em relação à receita liquida da empresa. Verifica-se também que o número de empregados em 2009 diminuiu em relação ao ano anterior, no entanto o número de mulheres aumentou de 4.096 em 2008, para 4.152 em 2009.

Tabela 3 - Análise dos indicadores externos

\begin{tabular}{|c|c|c|c|c|c|}
\hline $\begin{array}{l}1 \text { - BASE DE } \\
\text { CÁLCULO }\end{array}$ & \multicolumn{2}{|l|}{2009} & \multicolumn{2}{|l|}{2008} & $\begin{array}{c}\text { Análise } \\
\text { Horizonta } \\
\text { l }\end{array}$ \\
\hline Receita líquida (RL) & \multicolumn{2}{|c|}{$\begin{array}{c}\mathrm{R} \$ \\
390.277 .000,00\end{array}$} & \multicolumn{2}{|c|}{$\begin{array}{c}\mathrm{R} \$ \\
352.650 .000,000\end{array}$} & 10,67 \\
\hline $\begin{array}{l}\text { 3 - INDICADORES } \\
\text { SOCIAIS EXTERNOS }\end{array}$ & VALOR & $\begin{array}{l}\mathrm{AV} \\
(\%)\end{array}$ & VALOR & $\begin{array}{l}\mathrm{AV} \\
(\%)\end{array}$ & $\mathrm{AH}(\%)$ \\
\hline Educação & $\begin{array}{c}\mathrm{R} \$ \\
470.000,00\end{array}$ & 0,12 & $\begin{array}{c}\mathrm{R} \$ \\
1.122 .000,00\end{array}$ & 0,32 & $-58,11$ \\
\hline Cultura & $\begin{array}{c}\mathrm{R} \$ \\
200.000,00\end{array}$ & 0,05 & $\begin{array}{c}\mathrm{R} \$ \\
391.000,00\end{array}$ & 0,11 & $-48,85$ \\
\hline $\begin{array}{l}\text { Combate à fome e } \\
\text { segurança alimentar }\end{array}$ & $\mathrm{R} \$$ & 0,00 & $\begin{array}{c}\mathrm{R} \$ \\
46.000,00\end{array}$ & 0,01 & $-100,00$ \\
\hline $\begin{array}{l}\text { Outros (doação asilo e } \\
\text { seleção APAE). }\end{array}$ & $\begin{array}{c}\mathrm{R} \$ \\
1.060 .000,00\end{array}$ & 0,27 & $\begin{array}{c}\mathrm{R} \$ \\
668.000,00\end{array}$ & 0,19 & 58,68 \\
\hline $\begin{array}{l}\text { Total das contribuições } \\
\text { para a sociedade }\end{array}$ & $\begin{array}{c}\mathrm{R} \$ \\
2.364 .000,00\end{array}$ & 0,61 & $\begin{array}{c}\mathrm{R} \$ \\
2.697 .000,00\end{array}$ & 0,76 & $-12,35$ \\
\hline Tributos (excluídos & $\mathrm{R} \$ 54.886 .000,00$ & 14,06 & $\mathrm{R} \$$ & 10,6 & 46,35 \\
\hline
\end{tabular}




\begin{tabular}{|c|c|c|c|c|c|}
\hline encargos sociais) & & & $37.502 .000,00$ & 3 & \\
\hline $\begin{array}{l}\text { Total - Indicadores } \\
\text { sociais externos }\end{array}$ & $\begin{array}{c}\mathrm{R} \$ \\
5.725 .000,00\end{array}$ & 1,47 & $\begin{array}{c}\mathrm{R} \$ \\
40.199 .000,00\end{array}$ & $\begin{array}{c}11,4 \\
0\end{array}$ & $-85,76$ \\
\hline
\end{tabular}

Fonte: dados pesquisados (2011)

Quanto aos indicadores sociais externos, o indicador com maior investimento em 2008 foi Educação, com 0,32\%. Entretanto, mostrou queda em 2009, ficando em 0,12\%. Esta queda é evidenciada também na análise horizontal, com variação de $-58,11 \%$.

No indicador Cultura, de acordo com a análise vertical houve queda, de 0,11\% em 2008 para $0,05 \%$ em 2009. Esta queda também fica evidente de acordo com a análise horizontal, de $48,85 \%$.

A conta com menor investimento em 2008 foi de Combate a Fome e Segurança Alimentar, com $0,01 \%$. Este investimento não foi realizado em 2009, ficando em $0 \%$. Isso representa redução de $100 \%$ na análise horizontal.

Na sequência, verifica-se o indicador Outros (doação asilo e seleção APAE), com 0,19\% em 2008 e um aumento no período seguinte para $0,27 \%$, tornando-se o indicador externo mais expressivo de 2009. Este aumento é o segundo maior de acordo com análise horizontal, ficando em $58,68 \%$ de variação positiva.

\subsection{Análise do Balanço Social da empresa B}

A seguir analisam-se os Indicadores Sociais Internos, no entanto, é importante lembrar que a empresa não especificou o modelo de Balanço Social. Concluiu-se, então, que a empresa utiliza modelo próprio. Para fins deste estudo, as informações disponibilizadas pela empresa no seu sítio eletrônico foram adaptadas para o modelo de Balanço Social do IBASE.

O valor dos Encargos Sociais Compulsórios, que da empresa anterior foi a informação com maior expressividade, apesar de não fazer parte da análise devido a obrigatoriedade, nesta empresa não foi revelado o valor.

Há outros diversos valores que não aparecem no Balanço Social desta empresa. A fim de sanar as dúvidas existentes ou o saldo destes indicadores, houve uma tentativa de contato com a empresa em questão. A empresa respondeu explicando que devido às inúmeras solicitações que a empresa recebe diariamente requerendo informações, estudos e entrevistas, foi estabelecida uma cota de auxílio a estudantes, e no momento a cota está comprometida e por isso não será possível auxiliar no desenvolvimento do trabalho.

Tabela 4 - Análise dos indicadores sociais internos

\begin{tabular}{l|c|c|c}
\hline $\begin{array}{l}\text { 1 - BASE DE } \\
\text { CÁLCULO }\end{array}$ & $\mathbf{2 0 0 9}$ & $\mathbf{2 0 0 8}$ & $\begin{array}{c}\text { Análise } \\
\text { Horizonta } \\
\mathbf{1}\end{array}$ \\
\hline Receita líquida (RL) & $\mathrm{R} \$$ & $\mathrm{R} \$$ & 53,61 \\
\hline
\end{tabular}




\begin{tabular}{|c|c|c|c|c|c|}
\hline $\begin{array}{l}2 \text { - INDICADORES } \\
\text { SOCIAIS INTERNOS }\end{array}$ & VALOR & $\begin{array}{l}\text { AV } \\
(\%)\end{array}$ & VALOR & $\begin{array}{l}\text { AV } \\
(\%)\end{array}$ & AH (\%) \\
\hline Alimentação & $\begin{array}{c}\mathrm{R} \$ \\
5.028 .000,00\end{array}$ & 0,64 & $\begin{array}{c}\mathrm{R} \$ \\
3.842 .000,000\end{array}$ & 0,75 & 30,87 \\
\hline $\begin{array}{l}\text { Capacitação e } \\
\text { Desenvolvimento } \\
\text { profissional }\end{array}$ & $\begin{array}{c}\mathrm{R} \$ \\
240.000,00\end{array}$ & 0,03 & $\begin{array}{c}\mathrm{R} \$ \\
155.000,00\end{array}$ & 0,03 & 54,84 \\
\hline Creches ou auxílio-creche & $\begin{array}{c}\mathrm{R} \$ \\
101.000,00\end{array}$ & 0,01 & $\begin{array}{c}\mathrm{R} \$ \\
76.000,00\end{array}$ & 0,01 & 32,89 \\
\hline Transporte & $\begin{array}{c}\mathrm{R} \$ \\
3.052 .000,00\end{array}$ & 0,39 & $\begin{array}{c}\mathrm{R} \$ \\
2.323 .000,00\end{array}$ & 0,45 & 31,38 \\
\hline $\begin{array}{l}\text { Total - Indicadores } \\
\text { sociais internos }\end{array}$ & $\begin{array}{c}\mathrm{R} \$ \\
8.421 .000,00\end{array}$ & 1,06 & $\begin{array}{c}\mathrm{R} \$ \\
6.396 .000,00\end{array}$ & 1,24 & 31,66 \\
\hline
\end{tabular}

Fonte: dados pesquisados (2011)

Para análise, leva-se em consideração o corpo funcional da empresa.

O indicador social interno mais expressivo em 2008 foi Alimentação, com 0,75\%, e mesmo sendo o mais expressivo em 2009, houve queda para $0,64 \%$. O número de empregados ao final do período de 2008 é de 5.021, e este valor aumentou em 2009 para 5.740. Com isso, ratifica-se que houve queda de investimentos na alimentação dos empregados (apesar de podermos ver um aumento de $10,63 \%$ na análise horizontal).

Tabela 5 - Indicadores do corpo funcional

\begin{tabular}{|c|c|c|}
\hline 5 - INDICADORES DO CORPO FUNCIONAL & 2009 & 2008 \\
\hline $\mathrm{N}^{\mathrm{o}}$ de empregados (as) ao final do período & 5740 & 5021 \\
\hline $\mathrm{N}^{\mathrm{o}}$ de admissões durante o período & 3173 & 2171 \\
\hline $\mathrm{N}^{\mathrm{o}}$ de empregados (as) terceirizados (as) & 0 & 0 \\
\hline No de estagiários (as) & 12 & 2 \\
\hline $\mathrm{N}^{\mathrm{o}}$ de empregados (as) acima de 45 anos & 790 & 679 \\
\hline $\mathrm{N}^{\mathrm{o}}$ de mulheres que trabalham na empresa & 3859 & 3415 \\
\hline
\end{tabular}




\begin{tabular}{l|c|c}
\hline$\%$ de cargos de chefia ocupados por mulheres & 0 & 0 \\
\hline$N^{o}$ de negros (as) que trabalham na empresa & 79 & 20 \\
\hline$\%$ de cargos de chefia ocupados por negros (as) & 0 & 0 \\
\hline $\mathrm{N}^{\text {o de portadores (as) de deficiência ou necessidades }}$ & 87 & 2076 \\
especiais & 2441 & 538 \\
\hline $\mathrm{N}^{\mathrm{o}}$ de demissões e saídas no período & 562 & \\
\hline $\mathrm{N}^{\mathrm{o}}$ de pessoas beneficiadas com o primeiro emprego & & \\
\hline
\end{tabular}

Fonte: dados pesquisados (2011)

Os valores menos expressivos em 2008 foram do item Creche, em primeiro lugar, com $0,01 \%$, e Capacitação e Desenvolvimento Profissional, em $2^{\circ}$ lugar, com 0,03\%. As porcentagens permanecem inalteradas em 2009, apesar do número de empregados ter aumentado. Inclusive percebe-se aumento no número de mulheres trabalhando na empresa, que em 2008 eram 3.415 mulheres e em 2009 são 3.859, isto é, a empresa reduziu os investimentos em creche e desenvolvimento profissional e capacitação e desenvolvimento.

Apesar da análise vertical permitir tal conclusão, por meio da análise horizontal pode-se concluir que a empresa pode estar tentando melhorar neste aspecto, visto que a conta com maior aumento foi Capacitação e Desenvolvimento Profissional, na qual se investiu R\$ 155.000,00, em 2008, e R\$240.000,00, em 2009, representando a porcentagem de 54,84\%. E, a segunda conta com maior aumento foi Creche, onde a empresa destinou $\mathrm{R} \$ 76.000,00 \mathrm{em}$ 2008 e R \$ 101.000,00 em 2009, isto representa 32,89\% de aumento.

Outro indicador expressivo em 2009 foi Transporte, que em 2008 era de 0,45\% e em 2009 de 0,39\%. Apesar de ser o segundo mais expressivo em 2009, teve queda em relação a 2008. Como o número de empregados aumentou, podemos concluir que a empresa reduziu os investimentos com transportes (apesar da análise horizontal mostrar aumento de 31,38\%).

Tabela 6 - Análise dos indicadores sociais externos

\begin{tabular}{l|c|c|c|c|c}
\hline $\begin{array}{l}\text { 1 - BASE DE } \\
\text { CÁLCULO }\end{array}$ & \multicolumn{2}{|c|}{2009} & \multicolumn{2}{|c|}{$\mathbf{2 0 0 8}$} & $\begin{array}{c}\text { Análise } \\
\text { Horizontal }\end{array}$ \\
\hline Receita líquida (RL) & \multicolumn{2}{|c|}{ R $\$ 048.000,00$} & $514.916 .000,000$ & 53,61 \\
\hline 3- INDICADORES & VALOR & $\begin{array}{c}\text { AV } \\
\text { SOCIAIS EXTERNOS }\end{array}$ & VALOR & $\begin{array}{c}\text { AV } \\
(\%)\end{array}$ & AH (\%) \\
\hline Educação & R \$ & 0,00 & R \$ & 0,00 & 200,00 \\
\hline
\end{tabular}




\begin{tabular}{|c|c|c|c|c|c|}
\hline Cultura & $\begin{array}{c}\mathrm{R} \$ \\
354.000,00\end{array}$ & 0,04 & $\begin{array}{c}\mathrm{R} \$ \\
90.000,00\end{array}$ & 0,02 & 293,33 \\
\hline Esporte & $\begin{array}{c}\mathrm{R} \$ \\
1.163 .000,00\end{array}$ & 0,15 & $\begin{array}{c}\mathrm{R} \$ \\
602.000,00\end{array}$ & 0,12 & 93,19 \\
\hline Filantropia/ doações & $\begin{array}{c}\mathrm{R} \$ \\
139.000,00\end{array}$ & 0,02 & $\begin{array}{c}\mathrm{R} \$ \\
306.000,00\end{array}$ & 0,06 & $-54,58$ \\
\hline $\begin{array}{l}\text { Investimentos e } \\
\text { incentivos ao } \\
\text { voluntariado }\end{array}$ & $\begin{array}{c}\mathrm{R} \$ \\
7.000,00\end{array}$ & 0,00 & $\begin{array}{c}\mathrm{R} \$ \\
6.000,00\end{array}$ & 0,00 & 16,67 \\
\hline $\begin{array}{l}\text { Total das contribuições } \\
\text { para a sociedade }\end{array}$ & $\begin{array}{c}\mathrm{R} \$ \\
1.687 .000,00\end{array}$ & 0,21 & $\begin{array}{c}\mathrm{R} \$ \\
1.012 .000,00\end{array}$ & 0,20 & 66,70 \\
\hline $\begin{array}{l}\text { Total - Indicadores } \\
\text { sociais externos }\end{array}$ & $\begin{array}{c}\mathrm{R} \$ \\
1.687 .000,00\end{array}$ & 0,21 & $\begin{array}{c}\mathrm{R} \$ \\
1.012 .000,00\end{array}$ & 0,20 & 66,70 \\
\hline
\end{tabular}

Fonte: dados pesquisados (2011)

O indicador Educação, conforme análise vertical, não se alterou. No entanto, na análise horizontal, houve um aumento de $200 \%$. Pode-se verificar que apesar dos investimentos em 2009 continuarem baixos em relação à Receita Líquida, percebe-se um esforço da empresa na tentativa de melhorar.

A empresa possui vários projetos que integram o indicador Educação: investimentos com uma grande instituição de ensino, parceria com o Serviço Nacional de Aprendizagem Industrial - SENAI para oferecer cursos gratuitos à comunidade, Projeto Começar de Novo, Escola do Futuro, entre outros.

O indicador com menor investimento em 2008 foi Cultura, com 0,02\%, entretanto, aumentou, em 2009, para 0,04\%. Analisando horizontalmente verifica-se que este aumento foi o mais expressivo dos indicadores sociais externos. De $\mathrm{R} \$ 90.000,00$, em 2008, para $\mathrm{R} \$ 354.000,00$, em 2009, ou seja, 293,33\% de aumento.

Quanto aos indicadores sociais externos, como valor mais expressivo, encontra-se Esporte, com $0,12 \%$, e obteve aumento em 2009 , com $0,15 \%$, permanecendo como o valor mais relevante. Este aumento pode ser comprovado segundo análise horizontal, com aumento de 93,19\%.

Em 2009, o valor menos expressivo é com Filantropia/doações, com 0,02\%. Este investimento teve redução em 2009, já que em 2008 representava $0,06 \%$ da receita líquida da empresa. $\mathrm{Na}$ análise horizontal, representa a conta que obteve maior redução, com um percentual de $-54,58 \%$.

\subsection{Sugestões para as empresas}

A empresa A, apresenta Balanço Social de acordo com o IBASE, porém incompleto. Por isso, sugere-se para que seja realizado o IBASE completo e se possível o GRI, assim abrirá um 
campo maior, inclusive no exterior e levando em consideração que a empresa possui filial no exterior, torna-se importante a elaboração e divulgação deste relatório.

Quanto aos Indicadores Sociais Internos, a empresa A poderia verificar se a redução apresentada quanto a Segurança e Saúde no Trabalho foi em consequiência a redução de empregados ou foi redução de investimentos. Já nos Indicadores Sociais Externos, verifica-se a maior redução conforme análise horizontal em Educação e em seguida Cultura, então se for possível para a empresa, propõe-se aumento de investimentos nestes indicadores.

A empresa B, possui Balanço Social de modelo próprio. Sugere-se, portanto, que a empresa utilize o Balanço Social preconizado pelo IBASE.

Referente aos Indicadores Sociais Internos, a empresa B poderia verificar se diminuiu a necessidade por parte dos funcionários de investimentos em Creches ou Auxílio-Creche, pois houve redução neste indicador, no entanto verifica-se aumento do número de funcionários, inclusive de mulheres. Houve também redução referente a Capacitação e Desenvolvimento Profissional, levando em consideração o aumento de empregados, sugere-se verificar o motivo da redução neste indicador. Quanto a Indicadores Sociais Externos, se for possível para a empresa, sugere-se um aumento nos investimentos referentes a Educação, Cultura e Filantropia/Doações.

\section{CONCLUSÃO E SUGESTÕES PARA TRABALHOS FUTUROS}

Foram analisadas duas empresas do ramo têxtil, com o objetivo de verificar a evolução dos seus investimentos. Buscou-se ainda investigar se os dados do Balanço Social condizem com a realidade das empresas e se têm evoluído de um ano para o outro. Para alcançar este objetivo, é realizada a análise dos Balanços Sociais de duas empresas.

A empresa A possui Balanço Social de acordo com o IBASE, porém incompleto. A empresa B possui modelo próprio de Balanço Social. Apesar de vários projetos de cunho social e ambiental, não constam no balanço ou em relatórios, todos os dados monetários.

As empresas demonstram interesses sociais e ambientais, mas ainda não evidenciam todos os valores monetários referentes aos investimentos. Por isso, não há como afirmar que todos os valores que constam dos balanços condizem com a realidade.

Quanto aos índices de maior relevância, coincide nos indicadores sociais internos o de Alimentação. Ambas empresas diminuíram os investimentos neste quesito, conforme análise vertical. As empresas analisadas divergem quanto aos investimentos no indicador Educação e convergem no que diz respeito a importância dada à Cultura. A empresa A diminuiu o investimento em Educação, de acordo com as duas análises. Por sua vez, a empresa B manteve o nível de investimento com relação à Educação segundo a análise vertical e aumentou os valores na análise horizontal. No indicador Cultura, ambas aumentaram os montantes investidos nas duas análises.

Como limitação ao estudo, verifica-se que as informações são todas dos sites das empresas, houve contato com as empresas via email, uma das empresas respondeu as informações requeridas, enquanto a outra afirmou que no momento não pode fornecer informações.

Para trabalhos futuros sugere-se analisar os Balanços Sociais de outras empresas do setor têxtil a fim de comparar com as analisadas no estudo que se encerra. Também é possível realizar um trabalho propondo à empresa A um GRI e à empresa B um Balanço Social conforme o IBASE.

\section{REFERÊNCIAS}

R. Cont. Ufba, Salvador-Ba, v. 6, n. 1, p. 66-79, janeiro-abril 2012 
IBASE. Instituto Brasileiro de Análises Sociais e Econômicas. Disponível em: $<$ http://www.ibase.br>. Acesso em: 01 mai. 2011.

INSTITUTO ETHOS DE EMPRESAS E RESPONSABILIDADE SOCIAL. Relatório de Sustentabilidade GRI. Disponível em:

<http://www1.ethos.org.br/EthosWeb/pt/1400/o_instituto_ethos/o_uniethos/o_que_fazemos/c ursos/relatorio_gri/relatorio_de_sustentabilidade_-_gri.aspx>. Acesso em: 01 ago. 2011

GIL, Antonio Carlos. Como elaborar projetos de pesquisa. 5.ed. São Paulo: Atlas, 2010.

MARCONI, Maria de Andrade; LAKATOS, Eva Maria. Fundamentos de metodologia científica. São Paulo: Atlas, 2009.

MARION, José C. Contabilidade Empresarial. 11. ed. São Paulo: Atlas, 2005.

PADOVEZE, Clóvis Luís. Contabilidade gerencial: um enfoque em sistema de informação contábil. 7. ed. São Paulo: Atlas, 2010.

PFITSCHER, Elisete Dahmer. Contabilidade e Responsabilidade Social . Departamento de Ciências Contábeis: Florianópolis, 2009.

RICHARDSON, Roberto Jarry. Pesquisa social: métodos e técnicas. 2 ed. São Paulo: Atlas, 1999.

TACHIZAWA, Takeshy. Gestão Ambiental e Responsabilidade Social Corporativa: estratégias de negócios focadas na realidade brasileira. 2. ed. revista e ampliada. São Paulo: Atlas, 2004.

TINOCO, João E. P.; KRAEMER, Elisabeth P. Contabilidade e Gestão Ambiental. São Paulo: Atlas, 2008. 